\title{
A dramaturgia e a encenação em Orfeu Mestiço
}

Quais são as relações entre dramaturgia e encenação no teatro hip-hop do Núcleo Bartolomeu de Depoimentos? Essa foi a questão que norteou o nosso diálogo com a diretora Claudia Schapira, tendo como foco o seu trabalho na direção e na escritura do texto de "Orfeu Mestiço - uma hip-hópera brasileira". A montagem é fruto do projeto contemplado pela Lei Municipal de Fomento ao Teatro, uma pesquisa que durou quase três anos e estreou na cidade de São Paulo, em outubro de 2011, tendo recebido algumas premiações significativas ${ }^{1}$. Atriz argentina radicada no Brasil, formada pela Escola de Arte Dramática da USP, Claudia Schapira trabalhou com importantes nomes do teatro brasileiro ${ }^{2}$ ao longo de sua trajetória. Foi uma das fundadoras do Núcleo em 2000 e co-coordenou eventos como o "DCC - Dramaturgia Concisa e Contemporânea, encontro aleatório entre dramaturgos e atores" e "Zap! Zona Autônoma da Palavra", o primeiro poetry slam (campeonato de poesia) brasileiro.

\section{Como você situa, do ponto de vista estético e político, a sua dramaturgia no cenário contemporâneo?}

Muito difícil avaliar a própria escrita... Mas, claro que ao longo de cada processo se acaba refletindo sobre os passos dados; se encontram pares, se vislumbram similitudes, diferenças e, por fim, se reconhece um lugar que é seu... Creio que por esta dramaturgia estar inserida em um contexto multidisciplinar, ou seja, diretamente ligada ao resultado buscado, ela é um recorte, uma mistura de influências e tendências que potencializam aquilo que quero dizer com a obra como um todo,

\footnotetext{
${ }_{1}^{1}$ Premio de melhor atriz e indicação para melhor direção musical no prêmio Shell de 2011, prêmio CPT de melhor projeto sonoro e a indicação de melhor projeto visual, tendo sido convidado para diversos festivais nacionais.

2 Ulisses Cruz, José Possi Neto, Cibele Forjaz, Luís Melo, Lu Grimaldi e Daniela Thomas, e no cinema, Tata Amaral, Fabrizia Pinto e Fernando Meireles.
} 
do que chamamos de teatro hip-hop. Tenho uma urgência e um interesse por falar do tempo que me toca viver... Associo isso, tanto à influência do teatro épico e da cultura hip-hop (nascidos ambos de uma inconformidade inerentes), como à ideia de presentificação da existência, de um pensamento mais quântico que permeia hoje também a minha criação. Sou apaixonada e ao mesmo tempo fruto das misturas, da diversidade, das injustiças, das divergências, da militância intrínseca que me constitui, da minha espiritualidade latente, da coexistência entre as antagonias impostas pela geografia urbana, e que acaba por imprimir grafismos próprios que se traduzem na obra de quem vive cosmopolita. Minha produção dramatúrgica se dá nessa fresta, nesse beco de encontros díspares, em lapsos como os que há entre a razão e a transcendência, entre o que é e o que deveria, entre a batida do coração e o ritmo frenético (antinatural), entre a inoperância de todas as coisas e o novo criativo que possa surgir dessa mesma inoperância.

Penso que o maior traço da minha dramaturgia no cenário contemporâneo é uma personalidade própria, inspirada pelas suas próprias necessidades e muito distante da busca por se enquadrar dentro de algum molde vigente ou de algum estilo específico. Não significa que não se enquadre, que não pertença, mas isso está longe de ser um mote relevante da pesquisa. Ela é, e aí sim, de uma maneira quase utópica, um desejo de falar sobre o que me tira o sono (a minha voz individual que se encontra com a voz-linguagem do outro criando um dizer comum) ganhando forma, gerando uma forma coletiva.

É uma dramaturgia que se sonha canção, que busca ritmo e poesia, que canta no intuito de constituir uma narrativa. É uma palavra musicada; é uma música que se apresenta, por vezes, trajetória de ação. Que segue um caminho próprio e muito particular. Ela nasce assim, indignada, ritmada, rimada, poética, musical, e isso sempre dialogou diretamente com os demais elementos da cena de forma igualitária. Nas nossas construções cênicas, criamos tudo junto e todos juntos! É um caos, mas é isso que potencializa a cena: A não subserviência dos elementos constitutivos da dramaturgia cênica. A letra e a música, os arranjos e a dança-gestus convergem para um mesmo discurso, um alinhavando o outro, um complementando o outro, ajudando a cena a se contar. Na verdade os elementos se interpenetram no jogo por dizer uma única coisa em uníssono. 


\section{Comente as opções da dramaturga/encenadora em relação à narrativa mítica do Orfeu.}

Mia Couto escreveu: "Toda história se quer fingir verdade. Mas a palavra é um fumo, leve demais para se prender na vigente realidade. Toda verdade aspira ser história..."

Foram três anos de pesquisa. Orfeu chegou no segundo ano. Durante esse período de construção da "hip-hópera" estudamos um sem-número de mitologias, e em determinado ponto do caminho vislumbramos no mito de Orfeu, uma fábula com abrangência de conteúdos, capaz de comportar em seu cerne as questões estéticas e temáticas que estávamos buscando. Assim, a "hip-hópera brasileira", até então centrada na construção de uma linguagem e na descoberta do imaginário de origem de formação do povo brasileiro (focada na questão da "mestiçagem"), acabou por somar a fábula de Orfeu para refletir - a partir de um recorte da história - sobre o amplo projeto de construção do povo-nação Brasil.

Escolha feita, o ensaio convergiu para a "viagem de descida aos infernos", utilizando o conceito de anjo da história, desenvolvido por Walter Benjamin, como voz reflexiva, em busca do recorte específico para sediar o ser social que encarnaria o nosso Orfeu, "um Orfeu mestiço," e inspirando a trama-sinopse do libreto hip-hoperístico que finalmente encenaríamos como "ode conclusiva" da longa pesquisa.

\section{Como se deu o processo de criação da dramaturgia da cena?}

O núcleo Bartolomeu de Depoimentos (como o próprio nome elucida) sempre cria a partir da ideia de depoimentos*. De personas em instâncias que corporificam uma determinada realidade e que será inserida em um contexto que expõe e dialetiza o seu significado. Dentro desse contexto, o que e quem, sempre foram os pontos mais relevantes. Perseguimos o mote, o que nos inquieta mediante as figuras que vivenciarão a narrativa. No processo Orfeu... foi a questão da mestiçagem, no sentido mais polêmico e abrangente, no sentido de esmiuçar as misturas, a alquimia que transforma as partes em outro elemento sem, no entanto, perder os elementos fundantes. $O$ olhar para trás de Orfeu e todas as suas implicações nos parecia o lugar no tempo-espaço perfeito! E como forma e conteúdo têm sido, dentro da nossa linguagem, elementos constitutivos da ideia de autorrepresentação*, a forma foi contaminada pelo mote. A ideia de uma "hip-hópera" é mestiça como proposição. Ela aponta as mesmas arestas contempladas na formação do povo brasileiro e isso ajudou no amálgama do espetáculo. A 
forma da cena comenta o seu próprio conteúdo, ora por revelação, ora por ironia, às vezes ainda por pura e clara evidência. (link inferno - 01:34:40 até 01:46:46)

Posto isso, buscamos a palavra de diversas maneiras. Se por um lado a primeira parte da pesquisa afunilou o conceito de depoimento para criar as ações cênicas, o procedimento seguinte aprofundou a práxis na construção gradual da dramaturgia, perseguindo a especificidade do verbo para compor a narrativa. Assim, trilhamos inicialmente o caminho do gesto (ação sem palavras), até chegar à palavra, que se lapidou, como consequência dessa pesquisa, em palavra essencialmente cantada. Foi mediante a construção de "silêncios histórico-celebráticos" (cenas gestuais, onde o movimento era o foco da ação para se chegar à síntese de cada passo do percurso da trajetória órfica), que nasceu a base do discurso falado do libreto.

Desenhamos silenciosos um percurso dançado, para chegar à ideia síntese contida em cada passo; para que finalmente, quando a palavra irrompesse, fosse essência: necessidade indispensável à ação. Uma narrativa precisa, urgente, em que a palavra cantada fosse prolongamento de cada movimento no espaço, em que a voz se estendesse como pirueta cortando o ar, em que as vozes, se entrelaçando, consagrassem os gestos coletivos. Realizada esta etapa, finalmente o libreto se consolidou trazendo ainda as seguintes premissas:

- uma dramaturgia que, mantendo as características originais de um libreto clássico, contempla-se uma forma narrativa mais recortada.

- a construção de uma "dramaturgia imagético-musical", em que a paisagem e o discurso sonoro, junto com a palavra, partilhassem da matriz constitutiva da "partitura", um discurso que propunha distintas formas e conteúdos, aplicando e reinventando conceitos que espelhassem as diversas vozes contidas nas diferentes modalidades cênicas (teatro, hip-hop, ópera), para materializar uma original e híbrida voz narrativa.

Somando a tudo isso, o pouso desse nosso Orfeu no período histórico da ditadura, período lacônico, cheio de ausências no nosso imaginário, de repercussões ainda escusas. Parece tanta coisa... e foi. O projeto ponto de partida se chamava Pajelança de Quarup no Congá - uma hip-hópera brasileira. Uma miscelânea, como a nossa formação, mas que quando esmiuçada é tão clara na sua compleição, que vai guiando passos certeiros. Hoje, quando vejo o resultado, percebo como de tanta coisa 
ficou um estilhaço, fragmentos, mas tudo está lá... e se organizou e se amalgamou e constituiu outra coisa repleta de todos os universos que percorremos.

Na dramaturgia de "Orfeu", a música, a palavra, a ação corporal e a imagem se complementam. A música, por exemplo, não está a serviço da ilustração do texto, ou instaurada como complemento secundário da cena, ela aparece como elemento constitutivo da dramaturgia.

Bom é um encontro de muitos caciques na sala de ensaio... e todos índios! porque é "tudo nosso", entende? Chegamos com gana total por fazer e aí primeiro uma exposição das ideias, uma experimentação de sonoridades, uma briga de foice, às vezes por defender os pontos de vista, mas sempre acabamos por encontrar um lugar de convergência, onde o que cada um vislumbrava se dá. A verdade que às vezes essa busca permeia toda uma temporada, anos de um espetáculo... o que não significa que ela não se materialize, mas sabemos que ela é apenas um esboço do que buscamos; outras cenas se revelam em sua magnitude sonhada na primeira tentativa... mistérios da criação... desafios de processo... outras proposições ainda, tenho a sensação, talvez as consigamos daqui a muito mais tempo... muitos vislumbres estão à frente de nós... na verdade é atrás disso que corremos a cada obra realizada e creio que isso não tem fim... mas existem coisas que a própria dramaturgia impõe. Quando escrevi o texto do coronel (link coronel/jornalista - 00:48:44 até 00:53:24), por exemplo, o texto foi inspirado em um tipo de melodiosidade que o Eugênio trouxe ao criar o depoimento daquela figura. Quando escrevi o texto final e inseri aquela personagem em outro contexto de cena, aquela sonoridade primeira interferiu diretamente na cadência da ação, nas pausas, nas curvas das frases. A sonoridade da persona interferiu na construção da dramaturgia escrita. Por outro lado, quando escrevi a "pária de Eurídice", eu já sentia a cadência do texto, a melodia e a métrica estavam esboçadas e a direção musical foi deflagrando esse desenho contido nas palavras, até se fundir com o texto, virando um só. São diferentes caminhos de um mesmo resultado com várias caras e jeitos.

A dança/gesto funciona um pouco da mesma maneira nos espetáculos. Buscamos a pulsação da rua e como ela pode se manifestar como gestus, como aspectos físico-motores das personagens. No Orfeu ainda havia o desafio de agregar a essa pulsação, o ritmo da pajelança como um latência intermitente; a movimentação das giras dos congás, aliadas a simples percursos. Foi essa a busca: misturar linguagens, como pessoas um dia se misturaram e deram origem a um povo, de forma 
desordenada e aparentemente aleatória, mas gerando movimentos surpreendentes e precisos, cadenciados, de beleza impar, como o povo brasileiro.

Assim, percorremos também o caminho da imagem. Sou apaixonada pela ideia das novas tecnologias interagindo com o caráter primordial do teatro. Mas sempre quis usar os recursos incríveis que essa nova mídia possibilita a serviço de uma narrativa concreta. Neste espetáculo ela permitiu criar tempos paralelos, elucidar planos, onde tempos diferentes dialogam, onde atores de corpo presente se encontram com sua própria imagem em outro tempo-espaço. Isso influenciou diretamente na dramaturgia. Tem cenas inteiras escritas a partir desse recurso. (link encontro de velhos amigos 01:04:50 até 01:06:24)

Como é a sua relação de dramaturga e encenadora com Eugênio Lima, um DJ, como parceiro de criação?

O DJ funciona na criação do teatro hip-hop como uma espécie de maestro. O toca-discos nos permite ancorar todo e qualquer tipo de música, de tendências, através dos samples $^{*}$. E como neste caso da hip-hópera teríamos também instrumentos ao vivo, a figura do DJ centralizou a organização das sonoridades. Cabe ressaltar que a figura do MC (mestre de cerimônias) complementa e auxilia essa orquestração na cena. No caso do Orfeu, mais especificamente, onde um dos atores-MCs vivencia a figura do griot-corifeu, comandando a trajetória. (link cena do festival - 00:26:21 até 00:29:57)

Como é a sua relação com Luaa Gabanini, que assina a direção de movimento e coreografia, no que diz respeito à formalização das ações e à presença virtual dos atores através da projeção de imagens tecnológicas?

Como em todos os campos, a criação é simultânea. No processo do Orfeu, quando criávamos uma cena, o pressuposto era que ela seria "dançada e cantada". Era o ponto de origem da construção.

O que não significava que toda cena surgia "cantada e dançada". Por vezes esse pressuposto se desdobrava em uma música lacônica gerada por um diálogo reticente, mais próxima de uma cena falada, mas o pulso interno era musical. Da mesma forma com o corpo. Quando pedia dança, a Luaa sabia que estava pedindo para que a cena não tivesse uma movimentação realista; que ela acompanhasse uma pulsação gerando um gestual extracotidiano. Isso pra mim é dança! Assim, partíamos da dança de rua, utilizada como comentário de ação. Parece vago, mais fica muito claro quando a cena acontece. É o caso do “jantar de família”. (Link do jantar - 01:10:36 até 01:13:57) 
ou na cena "canto pelo Brasil". A imagem percorreu em parte o mesmo caminho, embora não de forma tão imediata. Para a construção da imagem você necessita de toda a tecnologia que será utilizada na finalização e isso é praticamente impossível na nossa realidade de criação. Por isso eu, muitas vezes, acabo abrindo mão de possibilidades mais sofisticadas, para poder criar durante os ensaios. A imagem tem que fazer parte da criação cotidiana, senão ela não se integra. Ela chega como um elemento "estrangeiro". Eu queria que no Orfeu a imagem fosse personagem. Conseguimos criar um set "tosco" (manipulávamos o projetor na mão sugerindo o movimento que dois projetores realizariam mediante o uso de um programa de computador que é operado ao vivo etc.), mas que nos permitia experimentar o que o set final realizaria de modo mais elaborado. Assim, todas as imagens surgiram com e para a cena. Gostaria de ter ido ainda mais fundo na utilização da imagem, mas é o que deu pra criar junto. Preferi assim. Tem uma cena que gosto muito, um instante onde a imagem dança com o ritmo proposto pelo terreiro eletrônico. A imagem faz parte da banda naquele momento e esse lúdico me encanta. (link blues inferno - 01:38:38 até 01:41:07)

Como você vê a questão da mestiçagem na pesquisa sobre teatro hip-hop que vocês desenvolvem, configurando em cena diferentes matizes de cor, diferentes perspectivas culturais?

Autorrepresentação! Uma atitude deliberada de se servir da própria vida como "matéria bruta" e da paisagem que se habita (ágora permanente de ação), como interlocutores diretos da obra; utilizá-los como fonte e reflexão. Esse é a ideia que contempla o que você cita acima. Não tem como falar de mestiçagem se isso não se evidencia como um conflito real na cena, extensão do que somos e do que acreditamos. Não basta ser enunciado, tem que ser exposição. Nesse sentido não "inventamos universos", mas sim "escancaramos universos": os que frequentamos, os que nos permeiam, os que nos antagonizam. É uma postura sócio-político-cultural estética que se reflete na nossa criação, onde colocamos "arreganhando almas" o que somos e o que decidimos ser. Acreditamos assim a nossa criação. Nesse sentido, o nosso teatro abre mão, um pouco, da "Representação". E nisso se encontra com a cultura hip-hop, que se busca autoexpressão. Por outro lado, é um jogo de matizes, de pinceladas, onde você favorece as cores de modo a destacar diferentes contornos. Pois é óbvio que quando se assume o caráter espetacular de qualquer manifestação, ela vai reverberar um tom extracotidiano, e aí, meu irmão, é cena, querendo ou não. (link intermezzo Eugênio - 01:06:28 até 01:09:10) 
A maioria dos espetáculos de teatro em cartaz na cidade de São Paulo, atualmente, é dirigida e escrita por homens. No âmbito da cultura hip-hop, a predominância na produção de conteúdos é masculina. Como você vê a questão de gênero no Bartolomeu, um coletivo de expressão feminina majoritária?

A questão do feminino nos "últimos estertores" de uma sociedade patriarcal não é o nosso mote fundamental, mas está contemplada, não teria como não estar! (autorrepresentação) O primeiro espetáculo do Núcleo e que acabou por batizar o coletivo (“Bartolomeu que será que nele deu?"), se por um lado passava ao largo de qualquer tipo de conflito de gênero, por outro trazia isto posto na medida em que eram todas atrizes, representando personagens masculinos de terno e saia. Não era a questão, que impulsionou a criação do espetáculo, mas era um dado real, concreto e não tinha como, de alguma forma, não espelharmos nisso diversas questões sobre o papel social do feminino (autorrepresentação outra vez). Hoje penso mais claramente sobre isso, onze anos depois. Éramos cinco atrizes de um lado e o hip-hop do outro (um DJ, um MC e um percussionista, homens!). A contracena estética começou assim, e foi se transformando.

Hoje, a nossa formação é majoritária, mas não o nosso pensamento. Buscamos um equilíbrio real entre as partes! Licença poética ou não, quando falamos da nossa linguagem, falamos do teatro hip-hop como um "casamento estético". Mas é claro que a preponderância feminina acabou por elucidar uma vertente da cultura hip-hop mais "yin", muito diferente da matriz formadora dessa cultura. E isso cria outra forma de alavanca e de atrito. A contundência de uma MC mulher é forte em outro lugar. Traz à frente a questão da mulher no cenário mundial contemporâneo, não tem como! $\mathrm{E}$ isso sobrepõe significados. Quando uma atriz-MC faz um depoimento, para além da personagem e do discurso da mesma, evidencia um componente: uma mulher rapper, com um gestual próprio, engajado com a cultura de rua, mas de outro jeito.

Creio que a questão dos poucos nomes femininos dentro do cenário teatral talvez tenha a ver com essa dualidade do papel da mulher e com a própria inserção dela num cenário de ação mais efetivo! É estranho, me soa obsoleta essa frase, mas em algum lugar potente e latente sei que ainda reverbera; e muito! Mas como já falei, são os "últimos estertores" de uma sociedade patriarcal, e isso está morrendo, a passos largos! (ainda não como gostaria, mas afirmar isso me faz presentificar o futuro). Pelo menos em países como o Brasil; em outros lugares do planeta ainda se vive outro momento. Mas a verdade é que estamos vivendo vislumbres de outros tempos! Prefiro falar de coisas que hoje estão se tornando comuns e que seriam impensáveis há 20 
anos. Filhos de duas mães e de dois pais, para citar algo... Isso já não é uma utopia, é uma realidade. E daqui a pouco vai ser absolutamente cotidiano! Aí vai ser bom mesmo e a tal da igualdade, não mais um direito conquistado, mas uma expressão natural da vida! Utopias futuras... ainda!

\section{Comente o pressuposto irônico da adoção do termo hip-hópera brasileira.}

Mais do que discorrer sobre as especificidades de cada uma das partes envolvidas no neologismo "hip-hópera", prefiro falar sobre a transposição dos elementos que constituem a ópera para os termos que adotamos para configurar esses mesmos elementos na ideia de uma hip-hópera. O pressuposto irônico, melhor dizendo, crítico, está posto ali, na própria transposição e permeou todo o processo. Esses "termos-conceitos" foram introjetados na própria construção, e os tornou constitutivos da ação dramática.

A ideia de "atores-MCs cantoatuantes", com a mesma qualidade de interpretação e de potência musical.

A ideia de cantar transposta para o pressuposto: cantafalarolar!

A transposição das árias para a ideia de "párias", onde o "coro" e não o protagonista sustenta a voz principal da narrativa no sentido do comentário real que se quer fazer sobre a ação. (link nação zumbi - 00:37:25 até 00:41:08)

O coro transposto para a ideia de "coletivo dissonante", que não se apresenta como uma voz uníssona, mas sim como expoente da diversidade, do agrupamento de diferenças que formam um coletivo. (link corja - 01:57:12 até 01:59:48)

A ideia de "congá" como palco e cenário da ação.

- A transposição da ideia de fosso da orquestra (lugar onde ficam os músicos) para a construção de um "terreiro eletrônico", incluído no espaço fundamental da ação cênica e não separado.

- O contraponto entre "abertura" e "preâmbulo-prólogo", para a construção de uma instância musical híbrida que funcione como cena de apresentação. (link do prólogo "sou eu sou eu" - 00:05:41 até 00:07:41)

- A transposição dos "intermezzos" (cenas "des-tencionadoras" da ação dramática que podem acontecer entre os atos da ópera), para a ideia de "licenças poéticas elucidativas", funcionando antes como disparadores de conflitos, do que como "des-tensionadores".

- A transposição da figura do maestro para o coletivo de artistas que constitue o “terreiro eletrônico," perpassando a regência pela necessidade de cada cena (ora o DJ, ora o percussionista, ora o ator-MC), de acordo com a preponderância musical nela contida. 
- O uso do microfone como mais um instrumento constitutivo da "orquestra", buscando através dos atores/cantores que o usam, provocar as nuanças e as camadas musicais obtidas através da diversidade de timbres de diferentes instrumentos.

- A dança e o gestual como elementos fundamentais do movimento e da ação; como construção do percurso espacial e não apenas como ornamentos complementares do canto.

- A subtração da ideia do "virtuosismo" dando lugar à potência das manifestações genuínas e particulares de cada "persona social" encarnada na narrativa proposta e de cada artista que a expressa.

- A estrutura dos versos líricos, transposta no libreto para a máxima do hip-hop, que é o rap ("ritmo e poesia").

- A declamação entoada (feita para apresentar cada personagem da trama) transposta na ideia de "músicas-tema" (de personagens ou situações) ou instâncias musicais coletivas.

- Finalmente a transposição de uma narrativa lírica para uma narrativa épica com componentes dramáticos, situando a trajetória no tempo e no espaço, inserindo o contexto da ação na contemporaneidade.

\section{Comente a conexão da dramaturgia de Orfeu com a tradição musical brasileira.}

O libreto de Orfeu acabou por ser sediado em um determinado momento histórico brasileiro, considerado também um dos mais fortes da produção musical. Assim, o libreto que conta a história de Orfeu em três planos, em uma outra camada ainda, descreve a trajetória da música popular brasileira imbuída de sua pluralidade. A música conta o Orfeu, enquanto o tempo histórico do Orfeu coloca a música como protagonista de um tempo. Foi este jogo que elucidamos de cara entre dramaturgia e direção musical. $E$ isso se tornou alicerce de toda a encenação. Creio que a cena que mais revela esse jogo é a cena do festival. A música conta a história da peça, enquanto a atriz-MC mimetiza um cantor da época dos festivais; toda a construção musical é alinhavada por samples de temas-bordões dos festivais; a cena se conta e se canta a si mesma enquanto canta revelando a narrativa. (link cena do festival - 00:26:21 até 00:29:57) De outra maneira completamente diferente, mas buscando coisas parecidas, as escolas de samba e seus enredos, os blocos de rua e seus motes esboçam manifestações semelhantes. 


\section{Como é a relação da diretora com os atores-MCs?}

Eu sou atriz. A minha formação é de atriz. Tudo que comecei a fazer dentro da arte da cena foi a partir dessa ótica. Figurino, dramaturgia, direção... falo com eles como penso a cena... como eu criaria se estivesse criando um personagem em determinado momento... com as mesmas incertezas. Mas cada processo tem suas especificidades e os estopins de ação variam de acordo com essas especificidades. $O$ fato é como lidamos com uma linguagem múltipla, um pequeno estímulo gera resultados muito potentes e repletos de possibilidades. Um texto pode assumir inúmeras facetas dentro do que chamamos de "cena." Isso acumula material. Às vezes, tudo é aproveitado. Outras vezes, uma ideia se desdobra em outra coisa distinta, mas no final está tudo lá, exposto, transfigurado.

Algo essencial para a criação, e isso é extemporâneo, é a assimilação do que seja um ator-MC. O que chamamos de ator-MC é um artista "mestiço", um mix de intérprete com mestre de cerimônias. MC, não apenas como a figura do mestre de cerimônias da cultura hip-hop, mas também com uma voz coletiva. Enquanto $o$ ator personaliza e personifica, o MC redimensiona e amplia. Uma voz só evidenciando duas facetas em si mesmo e simultaneamente. É sutil e forte. Uma "Brincadeira de faz de conta verdadeira." O ator-MC vai evidenciar uma "visão de mundo" e isto, às vezes, parece um pouco difícil. Não se resolve com a construção de uma máscara nem com uma ação distanciada. É necessário buscar esse outro "lugar." Nesse sentido, a relação com o texto, ou a ideia de cena ou ainda de alguma persona sugerida, é fundamental. Porque, às vezes, a maneira como o texto está dividido, o raciocínio que ele propõe, esboça nas entrelinhas o desenho da personagem; a sonoridade, as pausas, os neologismos são matéria constitutiva. $\mathrm{E}$ o ator-MC vai seguindo essas pistas, criando um lugar, um como, um quem, apenas sugerido na ideia original. $\mathrm{O}$ ator-MC "sampleia" fisionomias, comportamentos, estados de espírito, gags etc. e os insere, os cita! Ao mesmo tempo os devora. (link ou te mato ou te quero - 00:31:46 até 00:35:43) Outras vezes, a dramaturgia propõe uma exposição de universo e discurso tão claros que o ator precisa encontrar a maneira de "encaixar" uma personagem na construção dramatúrgica proposta. (link daslú - 01:13:58 até 01:22:48) É uma relação de busca em parceria. Um caminho de mão dupla. Sou uma encenadora muito aberta, porque escrevo e porque no fundo, atuo. 


\section{Quais são seus mestres na linhagem da encenação brasileira? Quem Ihe influenciou?}

Penso que os que vieram antes e conseguiram trilhar uma trajetória que desenhou história, são nossos mestres. Seguimos o que eles lançaram, iscas, para que continuássemos!

Se eu falar de um, posso ser injusta com muitos, pois na verdade somos influenciados pelo entorno que constitui "o tempo que nos tocou viver" (adoro essa expressão!). Mas, sem dúvida, que há coisas que formam a matriz do que nos tornamos. Meus primeiros anos (até os 11) vivi onde nasci, em Buenos Aires. Lá o teatro é muito importante na formação infantil. Passei boa parte destes anos em salas de espetáculos. Lá o teatro é muito centrado na dramaturgia. E, sem dúvida, isso me influenciou muito. Por outro lado, existe um contexto geracional. Os meus anos de formação foram regados a Antunes Filho, Zé Celso e em diferente proporção, pela Cia. de Ópera Seca. Fora isso, existe um mundo de manifestações estéticas em todas as áreas que impregnaram minh'alma, que impressionaram meu olhar; e quando você vai criar, aparece tudo aquilo que te marcou! Gosto da idéia de recorte por isso. Partes diferentes que juntas esboçam uma outra coisa. Mosaico, recorte, colcha de retalhos, misturas, colagens, samples! Tudo isso me constitui, me influencia, e reverbera o que sou e, naturalmente, o que faço.

Não tenho uma linhagem única ou tão forte que caracterize o trabalho que desenvolvo no coletivo Bartolomeu! Mas sou um pouco de tudo o que vi, vivenciei e absorvi dos espetáculos que assisti até hoje. Ir ao teatro é uma experiência única, sempre. É um desnudamento profundamente humano e imperfeito! Agradeço!!! No mais, sei que o que reverbera muito é a urbanidade. A vida cosmopolita. Sou feita e resultado direto das grandes cidades. Por isso, reverencio sempre, "a rua", alimento cotidiano com sua vertigem, sua voracidade, sua beleza inusitada, suas pontas agudas; formada de sua crueza, de sua rudeza, de suas impossibilidades que me tornam quixotesca no querer cortar o vento com poesia e modificar a realidade... essa sim, está sempre presente, personagem protagonista de todos nossos cantos, escancarada, dissimulada, musa inalcançável de quem não decifra seus mistérios. 
O que te move para criar?

Existo porque crio

É o que nos cura

O que nos sustenta

O que nos alenta

Crio porque às vezes existo

$E$ insisto nos caminhos da arte

como mar, como barco

como porto de chegada

linguagem

língua que age! 